\title{
Occurrence of Lymphedema Following Sentinel Node Biopsy (SNB) for Lower Extremity Melanoma
}

\author{
Patrick D. Magoon ${ }^{\mathrm{a}}$, Roger A. Graham ${ }^{\mathrm{b}, \mathrm{d}}$, Janice G. Rothschild ${ }^{\mathrm{b}}$, Yoojin Lee
}

\begin{abstract}
Background: The benefits of sentinel node biopsy for melanoma are well established, while the risks have received less attention. This study was undertaken to establish the incidence of lower extremity lymphedema following inguinal SNB and to identify risk factors predictive for the development of lymphedema.
\end{abstract}

Methods: We conducted a retrospective chart review of all patients undergoing SNB at our institution between January 2000 and December 2007. Sixty-five patients were identified who had a lower extremity melanoma and underwent inguinal SNB in the absence of a completion lymph node dissection. After a minimum one year of follow-up, all patients were surveyed regarding their qualitative assessment of lymphedema.

Results: Forty patients returned surveys and are the subject of this study. Fourteen of 40 patients (35\%) reported experiencing postoperative lymphedema, with 9 patients $(23 \%)$ having lymphedema that persisted for more than 1 year. The onset occurred within 1 month of surgery in 8 patients $(25 \%)$. Lymphedema was described as minimal or mild by 13 patients and severe by 1 patient. Lymphedema requiring support stocking use was reported by 10 patients $(25 \%)$. An increased incidence of post-operative lymphedema was found to be associated with primary tumors located on the lower

Manuscript accepted for publication April 19, 2012

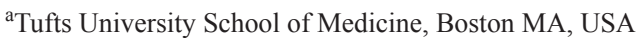

${ }^{b}$ Tufts Medical Center, Division of Surgical Oncology, Boston, MA, USA

${ }^{\mathrm{c}}$ Tufts Medical Center, Institute for Clinical Research and Health Policy Studies, Boston, MA, USA

${ }^{\mathrm{d} C}$ Corresponding author: Roger A. Graham, Tufts Medical Center, 800

Washington Street - Box 1043, Boston, MA 02111, USA.

Email: rgraham@tuftsmedicalcenter.org

doi: $10.4021 / \mathrm{jcs} 33 \mathrm{w}$ leg or foot.

Conclusions: Fourteen patients (35\%) undergoing inguinal SNB experienced post-operative lymphedema, with 9 patients $(23 \%)$ having persistent lymphedema for more than 1 year. These numbers are higher than in previously reported series. Location of the melanoma on the lower leg or foot appeared to be a significant risk factor.

Keywords: Melanoma; Sentinel node biopsy; Lymphedema

\section{Introduction}

For patients with melanoma, the benefits of sentinel lymph node biopsy (SNB) in the staging of regional lymph nodes has been confirmed both by an abundance of data demonstrating its prognostic efficacy [1-3] and by comparison with the morbidity of its predecessor - the elective lymph node dissection (ELND) [4-6]. In recent years, several studies have shown that SNB is considerably less morbid than ELND. Two large multi-institutional prospective studies have reported complication rates of $4.6 \%$ and $10.1 \%$ for SNB alone when compared with $23.2 \%$ and $37.2 \%$ for SNB plus completion lymph node dissection [7, 8]. In the report by Wrightson et al, the incidence of lymphedema following SNB was quoted as $0.66 \%$. When inguinal SNB was examined alone, the incidence of lymphedema increased to only $1.5 \%[7]$.

These studies have led to the widespread assertion that SNB is a safe and minimally invasive procedure. Data is limited, however, regarding the true incidence of lymphedema for patients undergoing SNB for lower extremity melanoma. Since this complication can have significant adverse consequences on a patient's quality of life and is potentially permanent, we decided to evaluate our own experience with this issue. Insight into the occurrence of lymphedema and risk factors leading to its development could also potentially lead to further reductions in the complications associated with SNB. This study was therefore done to establish the incidence of lymphedema following SNB for lower extremity 
Table 1. Patient Clinico-Pathologic Features $(n=40)$

\begin{tabular}{|c|c|}
\hline Characteristic & n (\%) \\
\hline \multicolumn{2}{|l|}{ Age at diagnosis (years) } \\
\hline Median & 61.5 \\
\hline Range & $26-85$ \\
\hline \multicolumn{2}{|l|}{ Sex } \\
\hline Male & $14(35)$ \\
\hline Female & $26(65)$ \\
\hline \multicolumn{2}{|l|}{ Body Mass Index $\left(\mathrm{kg} / \mathrm{m}^{2}\right)$} \\
\hline Mean & 26.54 \\
\hline$\leq 24.99$ & $19(47.5)$ \\
\hline $25-29.99$ & $13(32.5)$ \\
\hline $30-34.99$ & $4(10)$ \\
\hline$\geq 35$ & $4(10)$ \\
\hline \multicolumn{2}{|l|}{ Tumor location } \\
\hline Above knee & $22(55)$ \\
\hline Below knee/foot & $18(45)$ \\
\hline \multicolumn{2}{|l|}{ Breslow depth (mm) } \\
\hline Mean & 2.15 \\
\hline \multicolumn{2}{|c|}{ Number of sentinel nodes removed } \\
\hline Mean & 3.1 \\
\hline Range & $1-9$ \\
\hline 1 & $6(15)$ \\
\hline $2-3$ & $23(58)$ \\
\hline $4+$ & $11(27)$ \\
\hline \multicolumn{2}{|l|}{ Ulceration } \\
\hline Present & $10(25)$ \\
\hline \multicolumn{2}{|l|}{ Regression } \\
\hline Present & $7(17)$ \\
\hline
\end{tabular}

melanoma and to identify potential risk factors that might be predictive of post-operative lymphedema.

\section{Materials and Methods}

A database of all patients who underwent SNB at Tufts Medical Center for cutaneous melanoma between January 2000 and December 2007 was reviewed. Inclusion criteria included living patients who had a lower extremity melanoma $\geq 1$ $\mathrm{mm}$ in depth and underwent inguinal SNB with or without concomitant iliac SNB. All patients were operated on by one of two surgeons (RG and JR). Sentinel node location was mapped with preoperative lymphoscintigraphy. Intraoperatively, sentinel nodes were identified with a handheld gamma probe detector and visualized following an intradermal injection of isosulfan or methylene blue dye. Patients with positive sentinel nodes who underwent completion lymph node dissection (CLND) were excluded from analysis. Review of operative notes, pathology results, and nuclear medicine reports provided details concerning the location and number of sentinel nodes removed. 
Table 2. Post-Operative Lymphedema: Onset and Duration $(n=14)$

\begin{tabular}{lll}
\hline & $\begin{array}{l}\text { Onset of lymphedema } \\
\text { following surgery }\end{array}$ & $\begin{array}{l}\text { Duration of } \\
\text { lymphedema }\end{array}$ \\
\hline$<1$ month & 8 & 1 \\
$1-6$ months & 3 & 1 \\
$6-12$ months & 2 & 3 \\
$>12$ months & 1 & 9 \\
\hline
\end{tabular}

After a minimum 1 year follow-up, patients were sent questionnaires regarding their qualitative assessment of post-operative lymphedema. The investigators defined postoperative lymphedema to the survey respondents as any enlargement or swelling of the foot or leg and did not include swelling associated with the surgical incision. The questionnaires then asked patients to comment on the following: (1) presence or absence of lymphedema; (2) onset of lymphedema (<1 month vs $>1$ month); (3) severity of lymphedema (minimal/mild/severe); (4) duration of lymphedema (1 - 3 months/3 - 6 months/ 6 - 12 months/ > 12 months; (5) daily occurence of lymphedema (infrequent/after extensive standing/always present); and (6) use of a support stocking (no/ occasional/often/always). For data analysis, the authors defined lymphedema as any swelling (minimal/mild/severe) that persisted beyond 1 year or required support stocking use for management. Of note, no patients were referred for treatment of chronic lymphedema.

Statistical comparisons were made using the chi-squared test, Fisher's exact test, and Wilcoxon's two-sample test where appropriate; $p$ values $\leq 0.05$ were considered statistically significant. This study was approved by the institutional review board at Tufts Medical Center.

\section{Results}

We identified 65 patients who underwent SNB for lower extremity melanoma in the absence of a subsequent CLND from January 2000 to December 2007. Forty patients returned their questionnaires and are the subject of this study. There were 14 males and 26 females with a median age of 61.5 years (range $26-85$ years). Median time to follow-up was 30.5 months (range 12 - 94 months). Patient clinical and pathological characteristics are listed in Table 1.

\section{Patient assessment of lymphedema}

Fourteen of 40 patients (35\%) reported experiencing post- operative lymphedema, although only 9 patients had lymphedema that persisted beyond 1 year (23\%). Of those experiencing lymphedema, the onset occurred within 1 month of surgery in 8 patients $(25 \%)$ (Table 2 ).

The degree of swelling was described as minimal by 2 patients, mild by 11 patients, and severe by 1 patient. Ten patients elected to wear a support stocking and described wearing the stocking either on occasion (4 patients) or often/always (6 patients). Two patients reported limitations in their daily activities as a result of the swelling. Only 1 patient reported that he/she would not elect to have the SNB procedure again.

\section{Predictors of lymphedema}

Several potential risk factors for the development of post-operative lymphedema were assessed: age at diagnosis, gender, body mass index (BMI), location of the primary melanoma, surgical margin, type of wound closure, number of lymph nodes removed, concomitant removal of iliac lymph nodes, and operating surgeon. The only variable that was associated with an increased incidence of lymphedema was location of the primary tumor (Table 3). Lesions of the lower leg and foot were more frequently associated with post-operative lymphedema than lesions located above the knee $(78.6 \% \mathrm{v}$. $21.4 \%$, Fisher's, $\mathrm{P}<0.05$ ).

\section{Discussion}

Sentinel node biopsy has been widely adopted in the management of patients with melanoma $>1 \mathrm{~mm}$ in depth. Several recent studies have confirmed its widespread use and the attendant low risk of complications or significant morbidity. Most studies, however, have portrayed SNB as a single procedure without appropriate distinction of SNB involving cervical, axillary, and inguinal lymph node basins. When studies have focused on inguinal SNB alone, there was an increased morbidity when compared with SNB performed 
Table 3. Predictors of Lymphedema Following SNB

\begin{tabular}{|c|c|c|c|}
\hline Risk Factors & $\begin{array}{l}\text { Post-operative lymphedema } \\
(\mathrm{n}=14) \\
\mathrm{n}(\%)\end{array}$ & $\begin{array}{l}\text { No complications } \\
(n=26), n(\%)\end{array}$ & P value ${ }^{a}$ \\
\hline \multicolumn{4}{|l|}{ Gender } \\
\hline Male & $3(21.4)$ & $11(42.3)$ & $0.2992^{\mathrm{c}}$ \\
\hline Female & $11(78.6)$ & $15(57.7)$ & \\
\hline \multicolumn{4}{|l|}{ Surgeon } \\
\hline RG & $11(78.6)$ & $13(50.0)$ & $0.1010^{c}$ \\
\hline $\mathrm{JR}$ & $3(21.4)$ & $13(50.0)$ & \\
\hline \multicolumn{4}{|l|}{ Age at diagnosis } \\
\hline Mean (SD) & $57.8( \pm 16.4)$ & $60.6( \pm 15.9)$ & $0.5928^{\mathrm{b}}$ \\
\hline SEM (95\% CLM) & $4.4(48.3-67.2)$ & $3.1(54.1-67.0)$ & \\
\hline Median (range) & $60.5(35-84)$ & $64.5(26-85)$ & \\
\hline \multicolumn{4}{|l|}{ Tumor location } \\
\hline Above knee & $3(21.4)$ & $19(73.1)$ & $0.0027^{\mathrm{c}}$ \\
\hline Lower leg and foot & $11(78.6)$ & $7(26.9)$ & \\
\hline \multicolumn{4}{|l|}{ Surgical margins } \\
\hline $1 \mathrm{~cm}$ & $8(57.1)$ & $8(30.8)$ & 0.1044 \\
\hline $2 \mathrm{~cm}$ & $6(42.9)$ & $18(69.2)$ & \\
\hline \multicolumn{4}{|l|}{ Number of SNs removed } \\
\hline 1 & $2(14.3)$ & $4(15.4)$ & $1.0000^{\mathrm{c}}$ \\
\hline $2-3$ & $8(57.1)$ & $15(57.7)$ & \\
\hline $4+$ & $4(28.6)$ & $7(26.9)$ & \\
\hline \multicolumn{4}{|l|}{ Body mass index } \\
\hline Mean (SD) & $28.3(8.4)$ & $25.6(4.6)$ & $0.4738^{b}$ \\
\hline SEM (95\% CLM) & $2.2(23.5-33.1)$ & $0.9(23.7-27.4)$ & \\
\hline Median (range) & $25.15(22.3-52.3)$ & $25.05(18.1-36)$ & \\
\hline \multicolumn{4}{|l|}{ SN location } \\
\hline Inguinal & $8(57.1)$ & $17(65.4)$ & 0.6076 \\
\hline Inguinal and Iliac & $6(42.9)$ & $9(34.6)$ & \\
\hline \multicolumn{4}{|l|}{ Wound closure } \\
\hline Primary & $11(78.6)$ & $21(80.8)$ & $1.0000^{\mathrm{c}}$ \\
\hline Skin graft & $3(21.4)$ & $5(19.2)$ & \\
\hline
\end{tabular}

${ }^{a}$ chi-square unless otherwise noted; 'Wilcoxon's two-sample test; 'Fisher's exact test. 
at other sites $[9,10]$. It therefore seemed appropriate to not only evaluate the incidence of lymphedema associated with lower extremity melanomas, but to also search for risk factors predictive of who is at greatest risk for the development of lymphedema.

In the current study, the overall initial incidence of lymphedema following inguinal sentinel lymph node biopsy was $35 \%$, with $23 \%$ of patients describing lymphedema that persisted beyond 1 year. This incidence is higher than that reported in previous studies $(1.5-12 \%)$ but is consistent with the lack of consensus regarding the true incidence of lymphedema [7, 11, 12]. Furthermore, considerable variability exists amongst the techniques used for detecting and classifying lymphedema. The present study asked patients to document the presence or absence of lymphedema based on their own perception of swelling. In the report by Wrightson et al, there was no information provided for the methodology used in detecting lymphedema, nor was lymphedema classified according to severity. In the report by de Vries et al [11], limb volume was measured by volume displacement, with an increase of $6.5 \%$ being the cutoff for clinically significant lymphedema. The clinical relevance of using objective limb volume measurements as the definition for lymphedema has yet to be determined [13].

Additionally, recent studies in breast cancer patients have suggested that the subjective sensation of swelling and arm heaviness may in fact be predictive of progressive lymphedema [14, 15]. Due to the focus on patient-centered assessment, the present study's design likely allowed for the identification of minor degrees of swelling that would have previously gone unnoticed, as evidenced by 13 of 14 cases being subjectively classified as minimal or mild. By comparison, only 1 of $14(7.1 \%)$ cases was reported to be severe - an incidence that is similar to pre-existing reports of the incidence of lymphedema [16]. These subjective cases of mild lymphedema are unlikely to produce significant limb enlargement or findings on physical exam but are still significant based on patient perception and potential impairment to the patient. Knowledge of the real incidence of subjective lymphedema has implications for the care and counseling of the melanoma patient undergoing inguinal SNB - both in the pre-operative assessment of risks and benefits and in the coordination of care following surgery.

Previous authors have indicated that both the number of sentinel lymph nodes removed and the location of the nodal basin may serve as predictors of morbidity following SNB $[10,17]$. This study, however, failed to demonstrate a correlation between the number of nodes removed and the occurrence of lymphedema. Similarly, the risk of lymphedema did not increase when iliac lymph nodes were removed in addition to inguinal lymph nodes. Nevertheless, the present study did identify a novel risk factor specific to the development of lymphedema: primary tumors located below the knee. The relationship between lower leg melanoma and lymphedema has not been described elsewhere and its etiology is unclear. The smaller leg circumference and the increased density of lymphatics on the lower leg and foot [18] suggest that removing a greater percentage of the limb's lymph drainage via wide local excision may be responsible. However, data from the present study also found that larger surgical margins were not associated with lymphedema, implying that wide local excision alone is not the sole cause. Further research is needed to delineate the association between lymphedema and melanoma located below the knee.

Although the present study attempted to capture the true burden of post-operative lymphedema, there are several limitations to our data. Given that the occurrence of lymphedema was measured retrospectively by subjective reporting, our classification according to severity is not as valid as an objective measurement of limb volume. In addition, the role of reporting bias in distorting the true incidence of lymphedema must be considered. Lastly, alternative explanations for the high incidence of lymphedema in our series, such as failure of surgical technique, cannot be completely dismissed.

In summary, this study found that the incidence of postoperative lymphedema following an inguinal SNB was $35 \%$, with $23 \%$ of patients having persistent lymphedema beyond 1 year. Location of melanoma on the lower leg or foot was found to be a significant risk factor for developing lymphedema. Patients undergoing inguinal SNB should therefore be appropriately counseled and managed.

\section{Grant Support}

None.

\section{Financial Disclosures}

None.

\section{References}

1. Reintgen D, Balch CM, Kirkwood J, Ross M. Recent advances in the care of the patient with malignant melanoma. Ann Surg. 1997;225(1):1-14.

2. Tsao H, Atkins MB, Sober AJ. Management of cutaneous melanoma. N Engl J Med. 2004;351(10):998-1012.

3. Leong SP. Selective sentinel lymphadenectomy for malignant melanoma. Surg Clin North Am. 2003;83(1):157185 , vii.

4. Baas PC, Schraffordt Koops H, Hoekstra HJ, van Bruggen JJ, van der Weele LT, Oldhoff J. Groin dissection in the treatment of lower-extremity melanoma. Short-term and long-term morbidity. Arch Surg. 1992;127(3):281- 
286.

5. Urist MM, Maddox WA, Kennedy JE, Balch CM. Patient risk factors and surgical morbidity after regional lymphadenectomy in 204 melanoma patients. Cancer. 1983;51(11):2152-2156.

6. Bland KI, Klamer TW, Polk HC, Jr., Knutson CO. Isolated regional lymph node dissection: morbidity, mortality and economic considerations. Ann Surg. 1981;193(3):372-376.

7. Wrightson WR, Wong SL, Edwards MJ, Chao C, Reintgen DS, Ross MI, Noyes RD, et al. Complications associated with sentinel lymph node biopsy for melanoma. Ann Surg Oncol. 2003;10(6):676-680.

8. Morton DL, Cochran AJ, Thompson JF, Elashoff R, Essner R, Glass EC, Mozzillo N, et al. Sentinel node biopsy for early-stage melanoma: accuracy and morbidity in MSLT-I, an international multicenter trial. Ann Surg. 2005;242(3):302-311; discussion 311-303.

9. Hettiaratchy SP, Kang N, O'Toole G, Allan R, Cook MG, Powell BW. Sentinel lymph node biopsy in malignant melanoma: a series of 100 consecutive patients. $\mathrm{Br}$ J Plast Surg. 2000;53(7):559-562.

10. Wasserberg N, Tulchinsky H, Schachter J, Feinmesser M, Gutman H. Sentinel-lymph-node biopsy (SLNB) for melanoma is not complication-free. Eur J Surg Oncol. 2004;30(8):851-856.

11. de Vries M, Vonkeman WG, van Ginkel RJ, Hoekstra HJ. Morbidity after inguinal sentinel lymph node biopsy and completion lymph node dissection in patients with cu- taneous melanoma. Eur J Surg Oncol. 2006;32(7):785789.

12. Estourgie SH, Nieweg OE, Valdes Olmos RA, Hoefnagel CA, Kroon BB. Review and evaluation of sentinel node procedures in 250 melanoma patients with a median follow-up of 6 years. Ann Surg Oncol. 2003;10(6):681688.

13. Mittendorf EA, Hunt KK. Lymphatic interrupted: do we really understand the risks and consequences? Ann Surg Oncol. 2009;16(7):1768-1770.

14. Armer JM, Radina ME, Porock D, Culbertson SD. Predicting breast cancer-related lymphedema using selfreported symptoms. Nurs Res. 2003;52(6):370-379.

15. Norman SA, Localio AR, Potashnik SL, Simoes Torpey HA, Kallan MJ, Weber AL, Miller LT, et al. Lymphedema in breast cancer survivors: incidence, degree, time course, treatment, and symptoms. J Clin Oncol. 2009;27(3):390-397.

16. Wrone DA, Tanabe KK, Cosimi AB, Gadd MA, Souba WW, Sober AJ. Lymphedema after sentinel lymph node biopsy for cutaneous melanoma: a report of 5 cases. Arch Dermatol. 2000;136(4):511-514.

17. Roaten JB, Pearlman N, Gonzalez R, McCarter MD. Identifying risk factors for complications following sentinel lymph node biopsy for melanoma. Arch Surg. 2005;140(1):85-89.

18. Lubach D, Ludemann W, Berens von Rautenfeld D. Recent findings on the angioarchitecture of the lymph vessel system of human skin. Br J Dermatol. 1996;135(5):733-737. 